Supporting Information

\title{
Coupling Covalent Organic Frameworks and Carbon \\ Nanotube Membranes to Design Easily Reusable Photocatalysts for Dye Degradation
}

Hongbo Xue, Zhijie Bi, Jiayu Cheng, Sen Xiong* and Yong Wang*

State Key Laboratory of Materials-Oriented Chemical Engineering, and College of Chemical Engineering, Nanjing Tech University, Nanjing 211816, Jiangsu (P. R. China)

* Corresponding author. Tel.: +86-25-83172247; Fax: +86-25-83172292.

E-mail: xiongsenhg@njtech.edu.cn (S. Xiong) and yongwang@njtech.edu.cn (Y. Wang) 


\section{Table of Contents}

\begin{tabular}{|c|l|c|}
\hline Section & Name & Page No \\
\hline S1 & Mass Changes & 3 \\
\hline S2 & Water Contact Angles & 3 \\
\hline S3 & Equilibrium Adsorption Curves & 4 \\
\hline S4 & Degradation Performance Comparison & 4 \\
\hline S5 & Energy Band Structures & 5 \\
\hline S6 & Durability and Reusability & 6 \\
\hline S7 & References & 6 \\
\hline
\end{tabular}




\section{Section S-1: Mass Changes}

Table S1. Mass changes with different monomer concentrations.

\begin{tabular}{|c|c|c|c|}
\hline Monomer concentration & $0.3 \mathrm{mmol}$ & $0.5 \mathrm{mmol}$ & $1 \mathrm{mmol}$ \\
\hline Initial state & $24.7 \mathrm{mg}$ & $25.1 \mathrm{mg}$ & $23.8 \mathrm{mg}$ \\
\hline After reaction & $37.7 \mathrm{mg}$ & $40.1 \mathrm{mg}$ & $42.3 \mathrm{mg}$ \\
\hline Mass change & $13 \mathrm{mg}$ & $15 \mathrm{mg}$ & $18.5 \mathrm{mg}$ \\
\hline
\end{tabular}

\section{Section S-2: Water Contact Angles}

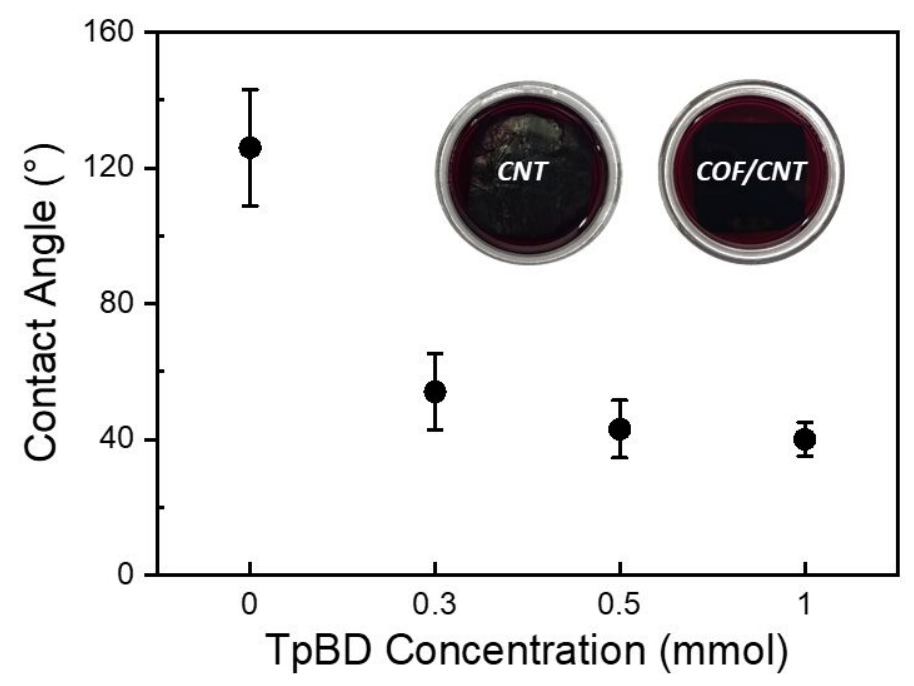

Figure S1. Water contact angles of CNT and COF/CNT membranes (insets show floating states of CNT and COF/CNT membranes in MB17 solutions). 


\section{Section S-3: Equilibrium Adsorption Curves}

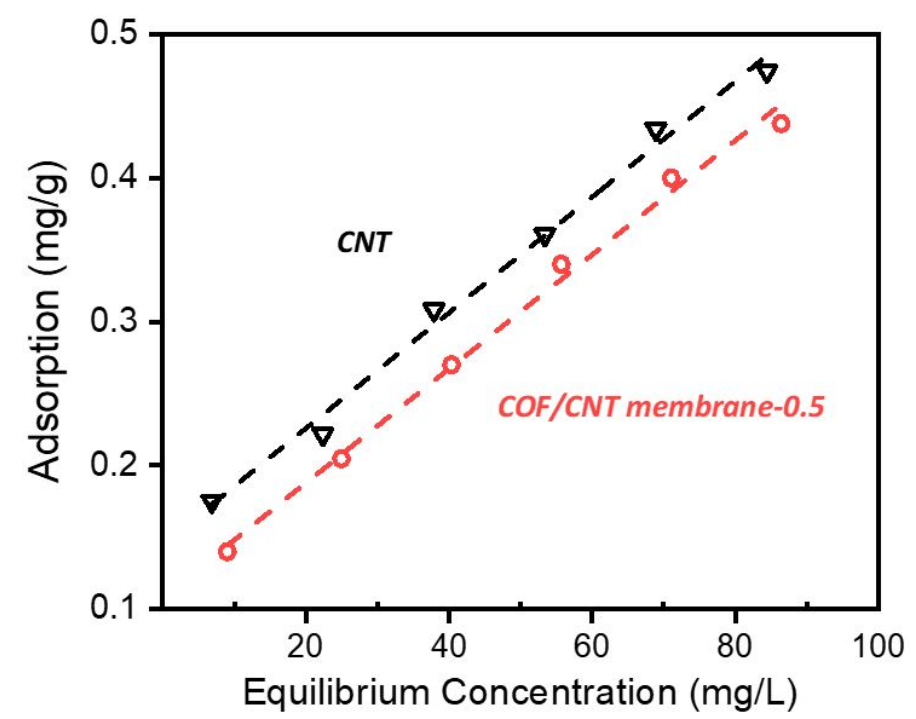

Figure S2. Equilibrium adsorption curves of $\mathrm{CNT}$ and $\mathrm{COF} / \mathrm{CNT}$ membranes.

\section{Section S-4: Degradation Performance Comparison}

Table S2. Comparison of photocatalytic efficiency of different catalysts.

\begin{tabular}{|c|c|c|c|c|}
\hline Category & Catalysts & Dyes & $\begin{array}{l}\text { Light } \\
\text { source }\end{array}$ & $\begin{array}{l}\text { Degradation in } 1 \mathrm{~h} \\
(\mathrm{mg} / \mathrm{g})\end{array}$ \\
\hline \multirow{2}{*}{ Inorganic } & $\mathrm{ZnO}^{1}$ & Methyl Violet & UV & 9.6 \\
\hline & $\mathrm{TiO}_{2}^{2}$ & $\begin{array}{l}\text { Methylene } \\
\text { Orange }\end{array}$ & UV & 80 \\
\hline Organic & $\mathrm{COP} / \mathrm{NT}+\mathrm{H}_{2} \mathrm{O}_{2}^{3}$ & Methylene Blue & $\operatorname{Vis}^{[\mathrm{a}]}$ & 5.13 \\
\hline \multirow{2}{*}{ Doped } & 5Fe-TiO $2 @ \mathrm{TpTa}^{4}$ & Methylene Blue & Vis & 19 \\
\hline & $\mathrm{g}-\mathrm{C}_{3} \mathrm{~N}_{4} / \mathrm{Ag}_{3} \mathrm{VO}_{4}{ }^{5}$ & Basic Fuchsin & Vis & 7.6 \\
\hline This work & $\begin{array}{c}\mathrm{COF} / \mathrm{CNT} \\
\text { membrane-0.5 }\end{array}$ & Mordant Black 17 & Vis & 351.56 \\
\hline
\end{tabular}

[a] Xe lamp simulated visible light. 


\section{Section S-5: Energy Band Structures}

The band gap of TpBD was calculated by the Kubelka-Munk function (Eq. S1) ${ }^{6}$ :

$$
(\alpha h v)^{n / 2}=A(h v-E g)
$$

where $\alpha$ represents the absorption factor, $h v$ is the photon energy, $n$ is the energy coefficient determined by the type of optical transition ( $n=1$ for direct transition, $n=$ 4 for indirect transition), $A$ is a constant, and $E g$ is the band gap.

The conduction band of the photocatalyst was calculated by the Mott-Schottky (M-S) analysis (Eq. S2 and S3) ${ }^{7}$ :

$$
\begin{gathered}
E_{C B}=E_{R H E}-0.2 \mathrm{~V} \\
E_{R H E}=E_{A g / A g C l}+0.059 \times p H+0.197 \mathrm{~V}
\end{gathered}
$$

where $E_{C B}$ is the conduction band potential $(\mathrm{eV}), E_{R H E}$ and $E_{A g / A g C l}$ are the flat band potential $(\mathrm{eV})$ based on the reversible hydrogen electrode and $\mathrm{Ag} / \mathrm{AgCl}$, respectively $(\mathrm{eV}$ ), and $0.2 \mathrm{~V}$ is the potential difference between the flat band and the conduction band. $p H$ is the potential of hydrogen of the test system.

(a)

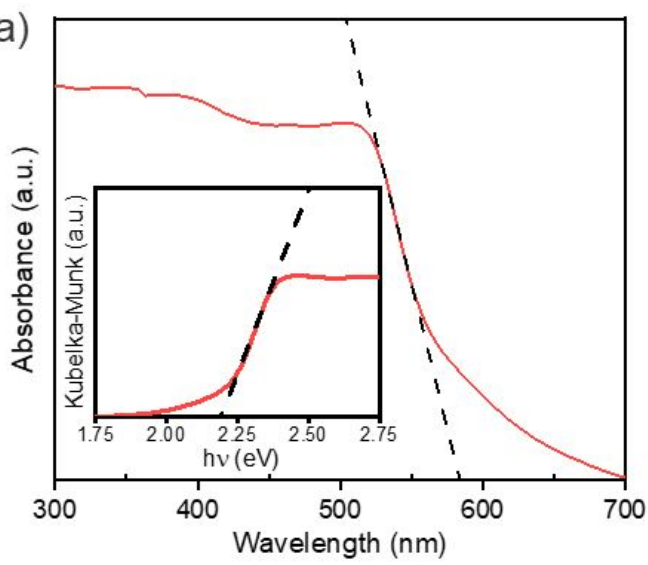

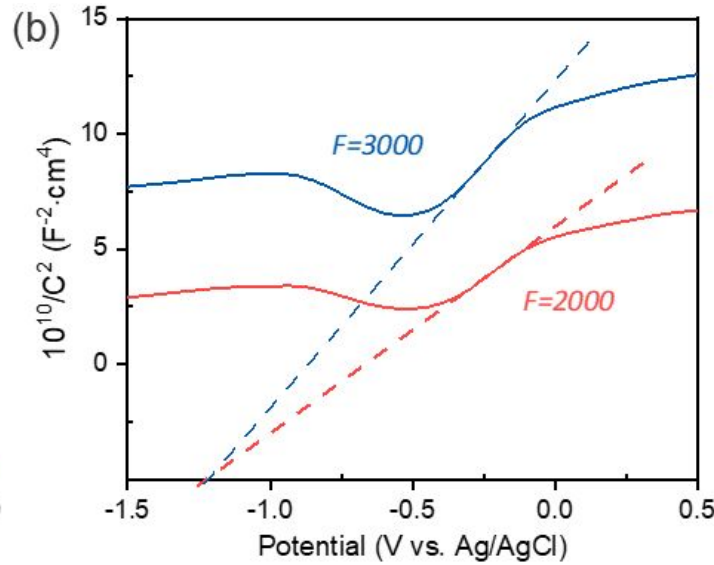

Figure S3. (a) DRS (inset shows the Eg determined by the Kubelka-Munk function) and (b) M-S curves of TpBD particulates at different frequencies. 


\section{Section S-6: Durability and Reusability}
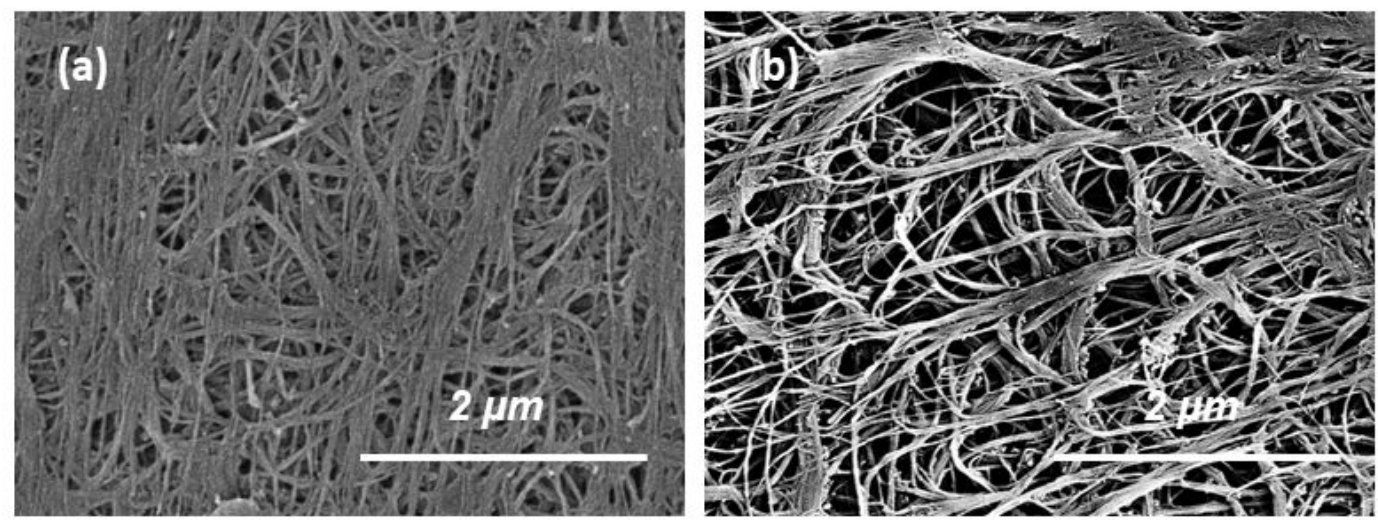

Figure S4. SEM images of (a) the pristine and (b) reused COF/CNT membrane-0.5.

\section{Section S-7: References}

(1) Song, C.; Yu, W.; Zhao, B.; Zhang, H.; Tang, C.; Sun, K.; Wu, X.; Dong, L.; Chen, Y. Efficient Fabrication and Photocatalytic Properties of $\mathrm{TiO}_{2}$ Hollow Spheres. Catal. Commun. 2009, 10, 650-654.

(2) Sun, J.; Dong, S.; Wang, Y.; Sun, S. Preparation and Photocatalytic Property of a Novel Dumbbell-Shaped Zno Microcrystal Photocatalyst. J. Hazard. Mater. 2009, 172, 1520-1526.

(3) Yu, C.; Cao, F.; Li, X.; Li, G.; Xie, Y.; Yu, J.; Shu, Q.; Fan, Q.; Chen, J. Hydrothermal Synthesis and Characterization of Novel $\mathrm{PbWO}_{4}$ Microspheres with Hierarchical Nanostructures and Enhanced Photocatalytic Performance in Dye Degradation. Chem. Eng. J. 2013, 219, 86-95.

(4) Cai, J.; Liu, W.; Li, Z. One-Pot Self-Assembly of $\mathrm{Cu}_{2} \mathrm{O} / \mathrm{RGO}$ Composite Aerogel for Aqueous Photocatalysis. Appl. Surf. Sci. 2015, 358, 146-151.

(5) Xu, N.; Wang, R.; Li, D.; Meng, X.; Mu, J. L.; Zhou, Z.; Su, Z. A New TriazineBased Covalent Organic Polymer for Efficient Photodegradation of Both Acidic and Basic Dyes under Visible Light. Dalton Trans. 2018, 47, 4191-4197.

(6) Lopez, R.; Gomez, R. Band-Gap Energy Estimation from Diffuse Reflectance Measurements on Sol-Gel and Commercial $\mathrm{TiO}_{2}$ : A Comparative Study. J. Sol-Gel Sci. Technol. 2012, 61, 1-7. 
(7) Giannakopoulou, T.; Papailias, I.; Todorova, N.; Boukos, N.; Liu, Y.; Yu, J.;

Trapalis, C. Tailoring the Energy Band Gap and Edges' Potentials of $\mathrm{g}-\mathrm{C}_{3} \mathrm{~N}_{4} / \mathrm{TiO}_{2}$ Composite Photocatalysts for $\mathrm{NO}_{x}$ Removal. Chem. Eng. J. 2017, 310, 571-580. 